\title{
Multi-curie production of gallium-68 on a biomedical cyclotron and automated radiolabelling of PSMA-11 and DOTATATE
}

Helge Thisgaard ${ }^{1,2^{*}}$ (D, Joel Kumlin ${ }^{3}$, Niels Langkjær ${ }^{1}$, Jansen Chua ${ }^{3}$, Brian Hook ${ }^{3}$, Mikael Jensen ${ }^{4}$, Amir Kassaian $^{3}$, Stefan Zeisler ${ }^{3}$, Sogol Borjian ${ }^{3}$, Michael Cross $^{3}$, Paul Schaffer ${ }^{3,5}$ and Johan Hygum Dam ${ }^{1,2}$ (B)

* Correspondence: helge.thisgaard@ rsyd.dk

'Department of Nuclear Medicine, Odense University Hospital, Kløvervænget 47, 5000 Odense, Denmark

${ }^{2}$ Department of Clinical Research, University of Southern Denmark, Odense, Denmark

Full list of author information is available at the end of the article

\begin{abstract}
Background: With increasing clinical demand for gallium-68, commercial germanium-68/gallium-68 $\left(\left[{ }^{68} \mathrm{Ge}\right] \mathrm{Ge} /\left[{ }^{68} \mathrm{Ga}\right] \mathrm{Ga}\right)$ generators are incapable of supplying sufficient amounts of the short-lived daughter isotope. In this study, we demonstrate a high-yield, automated method for producing multi-Curie levels of $\left[{ }^{68} \mathrm{Ga}^{\mathrm{G}} \mathrm{GaCl}_{3}\right.$ from solid zinc-68 targets and subsequent labelling to produce clinical-grade $\left[{ }^{68} \mathrm{Ga}\right] \mathrm{Ga}$ PSMA-11 and $\left[{ }^{68} \mathrm{Ga}\right] \mathrm{Ga}-D O T A T A T E$.

Results: Enriched zinc-68 targets were irradiated at up to $80 \mu \mathrm{A}$ with $13 \mathrm{MeV}$ protons for $120 \mathrm{~min}$; repeatedly producing up to $194 \mathrm{GBq}$ (5.24 Ci) of purified gallium-68 in the form of $\left[{ }^{68} \mathrm{Ga}_{\mathrm{GaCl}}\right.$ at the end of purification (EOP) from an expected $>370 \mathrm{GBq}(>10 \mathrm{Ci})$ at end of bombardment. A fully automated dissolution/separation process was completed in $35 \mathrm{~min}$. Isolated product was analysed according to the Ph. Eur. monograph for accelerator produced $\left[{ }^{68} \mathrm{Ga}_{\mathrm{GaCl}}\right.$ and found to comply with all specifications. In every instance, the radiochemical purity exceeded $99.9 \%$ and importantly, the radionuclidic purity was sufficient to allow for a shelf-life of up to $7 \mathrm{~h}$ based on this metric alone. Fully automated production of up to $72.2 \mathrm{GBq}\left[{ }^{68} \mathrm{Ga}\right] \mathrm{Ga}-\mathrm{PSMA}-11$ was performed, providing a product with high radiochemical purity $(>98.2 \%)$ and very high apparent molar activities of up to $722 \mathrm{MBq} / \mathrm{nmol}$. Further, manual radiolabelling of up to $3.2 \mathrm{GBq}$ DOTATATE was performed in high yields (> 95\%) and with apparent molar activities (9-25 MBq/ nmol) sufficient for clinical use.

Conclusions: We have developed a high-yielding, automated method for the production of very high amounts of $\left[{ }^{68} \mathrm{Ga}_{\mathrm{GaCl}}\right.$, sufficient to supply proximal radiopharmacies. The reported method led to record-high purified gallium-68 activities (194 GBq at end of purification) and subsequent labelling of PSMA-11 and DOTATATE. The process was highly automated from irradiation through to formulation of the product, and as such comprised a high level of radiation protection. The quality control results obtained for both $\left[{ }^{68} \mathrm{Ga}\right] \mathrm{GaCl}_{3}$ for radiolabelling and $\left[{ }^{68} \mathrm{Ga}\right] \mathrm{Ga}-\mathrm{PSMA}-11$ are promising for clinical use.
\end{abstract}

Keywords: Gallium-68, Cyclotron, Accelerator, DOTATATE, PSMA-11, Solid target, Targetry 


\section{Background}

In the 1960s, the first $\left[{ }^{68} \mathrm{Ge}\right] \mathrm{Ge} /\left[{ }^{68} \mathrm{Ga}\right] \mathrm{Ga}$-generators emerged and formed the early basis for modern, solid phase based generators of medical-grade gallium-68 ( $\mathrm{t}_{1 / 2}$ : $68 \mathrm{~min}$ ) (Gleason 1960; Greene and Tucker 1961; Yano and Anger 1964). Since then, generators remained as a reliable method for supplying this PET radionuclide for the development of novel radiotracers and imaging techniques. With diagnostic and therapeutic breakthroughs, particularly those in prostate cancer and neuroendocrine tumour imaging, the demand for gallium-68 is rapidly outpacing the supply available from $\left[{ }^{68} \mathrm{Ge}\right] \mathrm{Ge} /\left[{ }^{68} \mathrm{Ga}\right] \mathrm{Ga}$-generators.

Direct cyclotron production of gallium-68 using the ${ }^{68} \mathrm{Zn}(\mathrm{p}, \mathrm{n}){ }^{68} \mathrm{Ga}$ transformation on small medical cyclotrons provides access to clinically relevant quantities of the gallium-68 isotope. Liquid targets, using acidic solutions containing zinc-68 salts, are suitable for a small number of patient doses, but this method also carries the inherent risk of cyclotron damage upon target failure. Solid targets are more reliable and provide much higher yields, but until recently commercial systems capable of transporting solid targets by remote operation were limited and were not compatible with many selfshielded medical cyclotrons currently installed.

We report here on a high-yield automated method of producing $\left[{ }^{68} \mathrm{Ga}\right] \mathrm{GaCl}_{3}$ from solid targets and subsequent labelling to form $\left[{ }^{68} \mathrm{Ga}\right] \mathrm{Ga}$-PSMA-HBED-CC ( $\left[{ }^{68} \mathrm{Ga}\right] \mathrm{Ga}$ PSMA-11) and $\left[{ }^{68} \mathrm{Ga}\right] \mathrm{Ga}$-DOTATATE. Quality control tests were performed in accordance to the draft Ph. Eur. monographs (Gallium (68Ga) PSMA-11 Injection 2018; Gallium (68Ga) Chloride (Accelerator-Produced) Solution for Radiolabelling 2017), which, after the work was completed, have been released in their final versions to which both the $\left[{ }^{68} \mathrm{Ga}\right] \mathrm{GaCl}_{3}$ and $\left[{ }^{68} \mathrm{Ga}\right] \mathrm{Ga}-\mathrm{PSMA}-11$ still comply.

\section{Materials and methods}

\section{Materials}

All water was obtained from a Milli- $Q^{\bullet}$ Direct-Q 3 UV system (Merck Millipore). Ultrapur hydrochloric acid 30\% (Merck) was used directly and diluted with water during target dissolution and gallium-68 purification. Hydroxamate-based resin (ZR Resin), di(2ehtylhexyl)orthophosphoric acid-based resin (LN Resin) and trioctylphosphine-based resin (TK200 Resin) were used for $\left[{ }^{68} \mathrm{Ga}\right] \mathrm{GaCl}_{3}$ purification (Triskem International, Rennes, France). Labelling was performed with PSMA-11 and DOTATATE (ABX, Dresden, Germany).

\section{Irradiation}

Gallium-68 was produced via the ${ }^{68} \mathrm{Zn}(\mathrm{p}, \mathrm{n})^{68} \mathrm{Ga}$ nuclear reaction using highly enriched metallic zinc-68 solid targets (ARTMS, Vancouver, Canada, zinc-68: > 98.2\%, Ø10 mm, 230-315 mg on water cooled silver backing). The zinc-68 solid targets were transferred and irradiated using the ARTMS QUANTM Irradiation System ("QIS", ARTMS, Vancouver, Canada) on a GE PETtrace 880 Cyclotron (GEMS PET Systems AB, Uppsala, Sweden) using a helium-cooled aluminium foil energy degrader to achieve a proton incident energy of $13.0 \mathrm{MeV}$ on target. The targets were irradiated using proton beam currents of up to $80 \mu \mathrm{A}$ for up to $2 \mathrm{~h}$. Prior to applying the maximum beam current of $80 \mu \mathrm{A}$ on target, a series of beam current ramping experiments were performed on 
natural zinc targets. The irradiations were performed with increasing beam currents in steps of 5-10 $\mu \mathrm{A}$ (with all other parameters kept unchanged) followed by visual inspection of the irradiated target in each step.

\section{Target dissolution}

After irradiation, the target capsule (Fig. 1) was pneumatically transferred to a hot cell by the QIS. The zinc- 68 targets were then dissolved using $2 \mathrm{~mL}$ of hot (approx. $90{ }^{\circ} \mathrm{C}$ ) $30 \% \mathrm{HCl}$ on a QIS Dissolution System. Evolved hydrogen was vented.

\section{Purification}

The dissolved target solution containing $\left[{ }^{68} \mathrm{Ga}\right] \mathrm{GaCl}_{3}$ and $\left[{ }^{68} \mathrm{Zn}\right] \mathrm{ZnCl}_{2}$ was automatically transferred to a GE FASTlab 2 Developer synthesis module for separating the gallium-68 from the target material by three solid phase extraction columns (Fig. 2). First, the target solution was pumped through a column containing $250 \mathrm{mg}$ ZR resin. $15 \mathrm{~mL}$ of $30 \% \mathrm{HCl}$ were used to elute remaining zinc-68 from the $\mathrm{ZR}$ column, while gallium-68 was eluted from the column with $8 \mathrm{~mL}$ of $1 \mathrm{~N} \mathrm{HCl}$. The solution containing gallium-68 was pushed through the second column containing LN resin in order to bind Fe contaminants, while the eluted $\left[{ }^{68} \mathrm{Ga}\right] \mathrm{GaCl}_{3}$ was directly loaded onto a third column containing TK200 resin. The TK200 resin was dried by purging with nitrogen, then eluted to a product vial using $2.5 \mathrm{~mL}$ of $0.1 \mathrm{~N} \mathrm{HCl}$. The overall process of target dissolution and purification took approximately $35 \mathrm{~min}$.

\section{Quality control gallium-68}

Quality control of the produced $\left[{ }^{68} \mathrm{Ga} \mathrm{GaCl}_{3}\right.$ was performed according to the draft Ph. Eur. monograph on accelerator produced $\left[{ }^{68} \mathrm{Ga}\right] \mathrm{GaCl}_{3}$ (Gallium (68Ga) Chloride (Accelerator-Produced) Solution for Radiolabelling 2017).

Gamma-ray spectrometry and radionuclidic purity assays were performed using a calibrated Canberra Broad Energy Ge detector (BE2020, Canberra) equipped with Genie 2000 software. Half-life was determined by repeated measurements in a Capintec dose calibrator. $\mathrm{pH}$ was determined by $\mathrm{pH}$ sticks (Merck MColorpHast pH 0-6.0). The silver

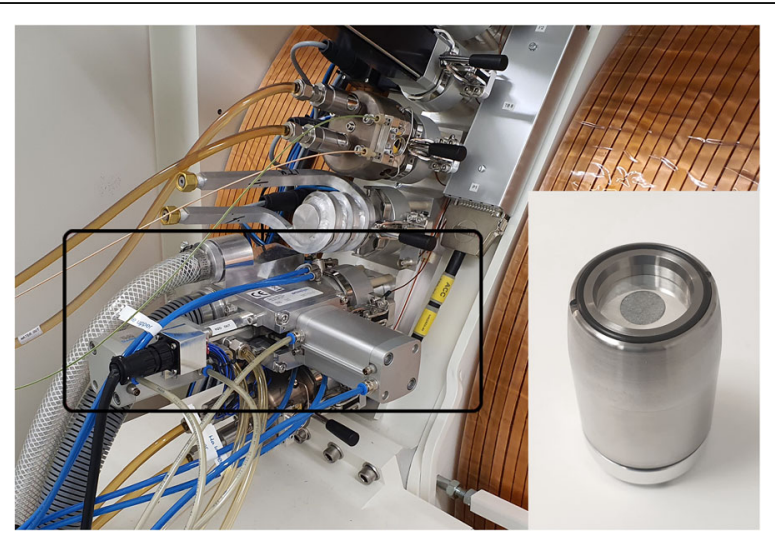

Fig. 1 The ARTMS QUANTM Irradiation System ${ }^{\circledR}$ on the GE PETtrace (rectangular box) allowing for automated pneumatic transfer of the water-cooled target capsule (insert) containing the enriched zinc-68 on silver backing 


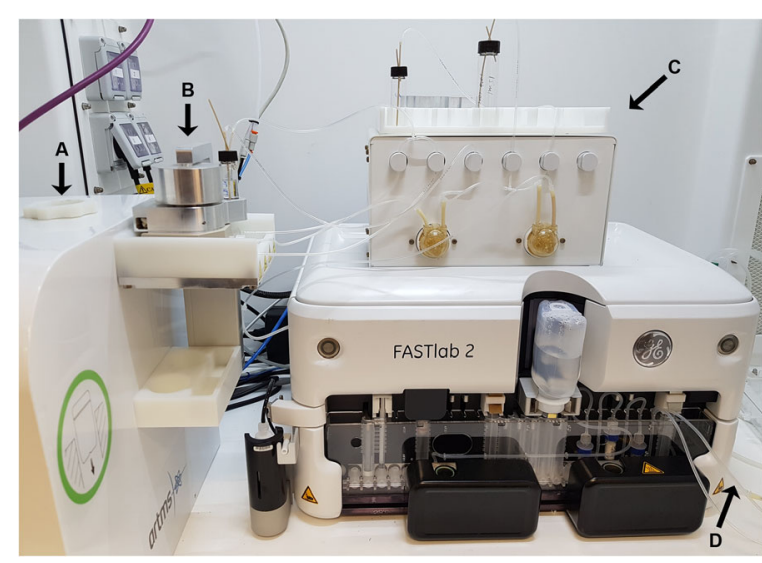

Fig. 2 ARTMS receive station (a), zinc-68 dissolution cell (b) and dissolution box (c) coupled to the GE FASTlab 2 Developer synthesis module with gallium-68/zinc-68 separation cassette installed. The ${ }^{68} \mathrm{Ga}^{-} \mathrm{GaCl}_{3}$ outlet (d) was connected to the Modular-Lab PharmTracer (not shown) for automated radiolabelling of PSMA-11

nitrate precipitation assay was performed by adding $5 \mu \mathrm{L}$ gallium- 68 chloride solution to $0.1 \mathrm{~mL}$ silver nitrate $(17 \mathrm{~g} / \mathrm{L})$ to yield a white precipitate. The solid phase extraction (SPE) assay was done by application of the Phenomenex Strata-X-C cation exchange cartridge $(33 \mu \mathrm{m}, 10 \mathrm{mg} / \mathrm{mL}$ ) preconditioned with $0.5 \mathrm{~mL}$ ethanol, then $1 \mathrm{~mL} 1.03 \mathrm{~g} / \mathrm{l}$ $\mathrm{HCl}$. The gallium-68 solution was slowly loaded onto the cartridge, the liquids collected and the column dried with air. The SPE column was washed with $1 \mathrm{~mL} \mathrm{HCl}(1.03 \mathrm{~g} / \mathrm{l})$ and the liquids were collected. The column was then eluted with $1 \mathrm{~mL} 2 \%(\mathrm{v} / \mathrm{v}) \mathrm{HCl}$ $(1.03 \mathrm{~g} / \mathrm{l})$ in acetone and dried with air to collect the final eluate. The quantity of radioactivity in each of the different fractions and the column were measured in the dose calibrator. Radiochemical purity was assessed by thin-layer chromatography on an Agilent ITLC-SG plate: A sample of the gallium-68 DTPA solution was added to the ITLC plate, which was eluted in 1:1 ammonium acetate $(77 \mathrm{~g} / \mathrm{l})$ : methanol over at least $7 \mathrm{~cm}$. The radioactivity distribution was evaluated on a MiniGita TLC scanner (Elysia-Raytest). Contents of iron and zinc were determined with semi-quantitative test strips (Quantofix ${ }^{\text {Tm }}$, Machery-Nagel) by comparing the colour change of the reactive pad against multi-stage colour scales. Further, the metal contents of decayed samples of the gallium-68 solution were quantified as described in draft Ph. Eur. monograph (Gallium (68Ga) Chloride (Accelerator-Produced) Solution for Radiolabelling 2017) by ICP-OES in an argon plasma (Thermo iCAP 6000 ICP Spectrometer, Thermo Scientific, Waltham, MA, USA). The contents of bacterial endotoxins was determined on an Endosafe Nexgen-PTS ${ }^{\mathrm{Tx}}$ by adjusting and diluting the $\mathrm{pH}$ of a sample to $\mathrm{pH}$ 6-8 with $\mathrm{NaOH}$ (10 $\mathrm{mM}$, in endotoxin free water (Charles River)) for minimum inhibition of the endotoxin assay before adding the solutions to the single use cartridge.

\section{Radiolabelling of DOTATATE with gallium- 68}

Zinc-68 targets containing $230-315$ mg zinc-68 were irradiated with $50-70 \mu \mathrm{A}$ for $0.5-$ $1 \mathrm{~h}$ and the produced gallium-68 was separated from target material as described above. Radiolabelling of DOTATATE with gallium-68 was performed manually. For labelling with low activity levels $(<1 \mathrm{GBq}, \mathrm{n}=3), 100 \mu \mathrm{l}$ of the purified gallium-68 
solution was used, while approximately $900 \mu \mathrm{l}$ was used for the single $3.2 \mathrm{GBq}$ labelling. For the low activity labelling, the $\left[{ }^{68} \mathrm{Ga}\right] \mathrm{GaCl}_{3}$ was microwave heated (CEM PETwave) to $90{ }^{\circ} \mathrm{C}$ for $2 \mathrm{~min}$. with $50 \mu$ g DOTATATE $(34.8 \mathrm{nmol}$ ) in $125 \mu \mathrm{l}$ acetate buffer (pH 4.6, Fluka) and $20 \mu \mathrm{l}$ ethanol added. For higher activity labelling $(3.2 \mathrm{GBq}$ ), the $\left[{ }^{68} \mathrm{Ga} \mathrm{GaCl}_{3}\right.$ solution was mixed with $500 \mu \mathrm{l}$ acetate buffer and then preheated to $95{ }^{\circ} \mathrm{C}$ before adding $500 \mu \mathrm{g}$ of DOTATATE $(348 \mathrm{nmol})$ in $100 \mu \mathrm{l}$ acetate buffer. The solution was kept at $95{ }^{\circ} \mathrm{C}$ for $10 \mathrm{~min}$. In all cases the labelling yield and radiochemical purity was assessed by ITLC (Biodex 150-771, 0.1 M sodium citrate, pH 5) and radio-HPLC on a Phenomenex Jupiter 300A $(150 \times 4.6,5 \mu \mathrm{m}) \mathrm{C} 18$ column in water $+0.1 \%$ TFA (A) and acetonitrile (B); 0-2 $\mathrm{min}$. $14 \% \mathrm{~B}, 2-10 \mathrm{~min}$. 14 to $63 \% \mathbf{B}$ at $1 \mathrm{~mL} / \mathrm{min}$. and UV detection at $220 \mathrm{~nm}$.

\section{Radiolabelling of PSMA-11 with gallium-68}

Zinc-68 targets containing 230-315 mg zinc-68 were irradiated with $80 \mu \mathrm{A}$ for $2 \mathrm{~h}$ and the produced gallium-68 was separated from the target material as described above. Radiolabelling of PSMA-11 with $\left[{ }^{68} \mathrm{Ga}\right] \mathrm{GaCl}_{3}$ was achieved with a single use kit on an automated Modular-Lab PharmTracer (Eckert \& Ziegler) in direct connection to the FASTlab synthesizer. The standard cassette was modified to accommodate acceleratorproduced gallium-68 radiolabelling Fig. 3, i.e. the cation exchange column was removed and the module was programmed to withdraw the gallium-68 solution from the FASTlab product vial and deliver $1.0 \mathrm{~mL}$ (out of the $2.2-2.4 \mathrm{~mL}$ total produced gallium-68

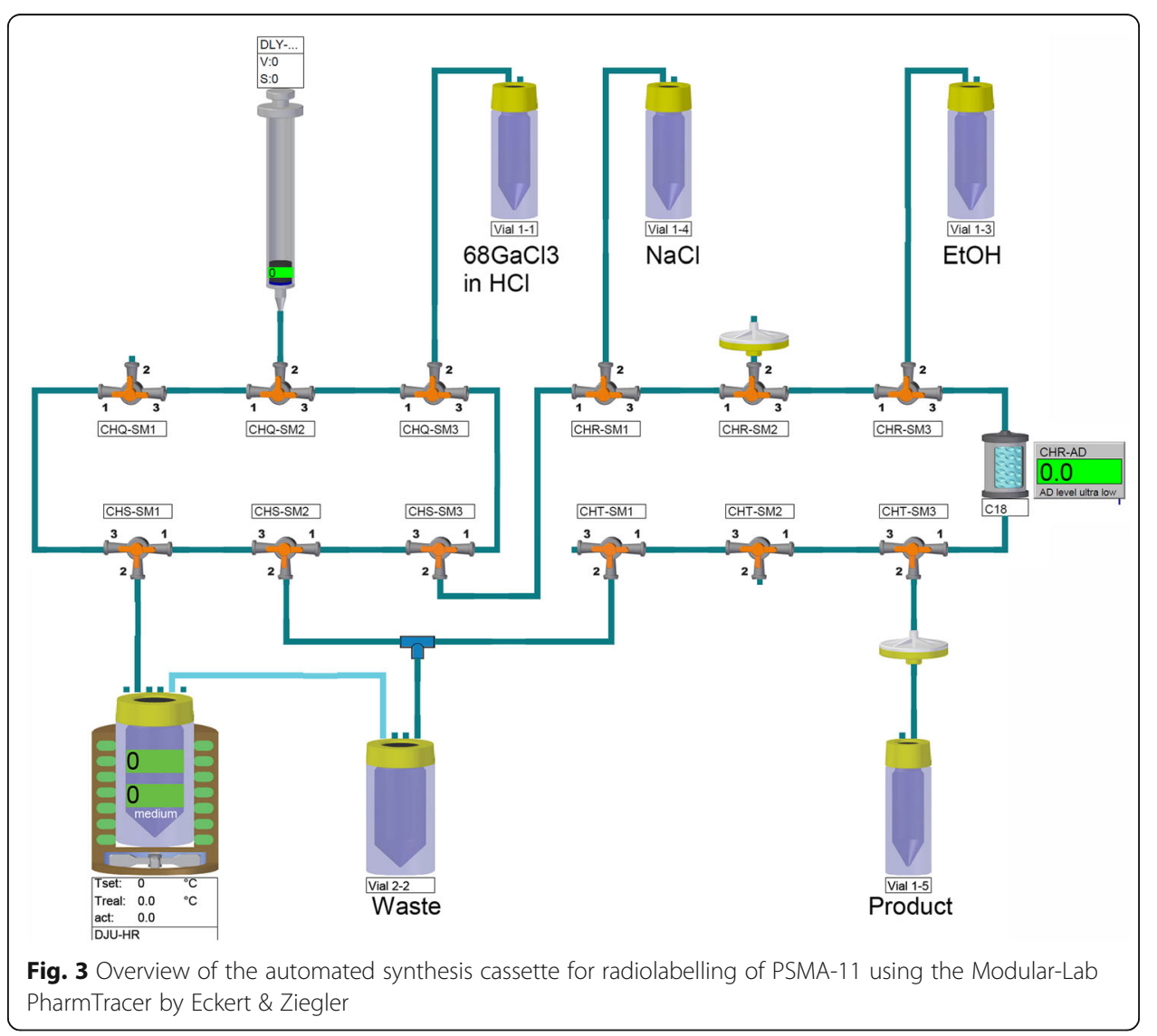


chloride solution) to the reactor. The reactor was also loaded with $50 \mathrm{mg}$ of sodium ascorbate, 100 nmol PSMA-11 (ABX, Germany) and $1.0 \mathrm{~mL}$ sodium acetate buffer, $\mathrm{pH}$ 4.6. During the labelling, the reactor was heated to $95{ }^{\circ} \mathrm{C}$ for $600 \mathrm{~s}$ after which the solution was diluted with $3 \mathrm{~mL}$ deionized (DI) water and loaded onto a preconditioned SepPak C18 light column. The reactor was further washed with $3 \mathrm{~mL}$ DI water and loaded onto the C18 light column, which was washed with $3 \mathrm{~mL}$ of DI water. The column was eluted with $2 \mathrm{~mL} \mathrm{50 \%} \mathrm{(v/v)} \mathrm{ethanol} \mathrm{followed} \mathrm{by} 4 \mathrm{~mL}$ DI water into a product vial containing $50 \mathrm{mg}$ sodium ascorbate in $6 \mathrm{~mL}$ phosphate buffered saline to yield a final product volume of approximately $12 \mathrm{~mL}$ containing the $\left[{ }^{68} \mathrm{Ga}\right] \mathrm{Ga}-\mathrm{PSMA}-11$ at the end of synthesis (EOS).

For quality control, an aliquot was analysed by HPLC on a Phenomenex Kinetex XBC18 column $(150 \times 4.6,5 \mu \mathrm{m}, 1 \mathrm{~mL} / \mathrm{min})$ applying a gradient program (A:B, DI water + $0.1 \%$ TFA: acetonitrile) similar to that specified in the Ph. Eur $\left[{ }^{68} \mathrm{Ga}\right] \mathrm{Ga}-\mathrm{PSMA}-11$ monograph draft, i.e. $0-0.5 \mathrm{~min}$. $5 \%$ B then $5-40 \%$ B from 0.5 to $10 \mathrm{~min}$ (Gallium (68Ga) PSMA-11 Injection 2018). Also, the amounts of unlabelled and colloid gallium68 were determined by TLC on silica gel on glass backing plates eluted in either $0.1 \mathrm{M}$ sodium citrate, $\mathrm{pH} 5$ or ammonium acetate in DI water $(77 \mathrm{~g} / \mathrm{l})$ :methanol 1:1, respectively. $\mathrm{pH}$ was checked by a calibrated $\mathrm{pH}$ meter.

\section{Results}

\section{Targetry and $\left[{ }^{68} \mathrm{Ga}\right] \mathrm{GaCl}_{3}$ productions}

During beam current ramping experiments, we determined that the zinc targets were capable of withstanding beam currents of at least $80 \mu \mathrm{A}$ of $13 \mathrm{MeV}$ protons for $2 \mathrm{~h}$, which is equivalent to approximately $1 \mathrm{~kW}$ of power deposited in the zinc target material.

Irradiations performed under these conditions $(80 \mu \mathrm{A}$ for $120 \mathrm{~min})$ produced up to $194 \mathrm{GBq}(5.24 \mathrm{Ci})$ of purified $\left[{ }^{68} \mathrm{Ga}\right] \mathrm{GaCl}_{3}$ at the end of purification (EOP) from an expected $>370 \mathrm{GBq}(>10 \mathrm{Ci}$ ) gallium-68 at end of bombardment (EOB). The fully automated dissolution/radiochemical separation was performed in $35 \mathrm{~min}$. Multiple productions were analysed according to the draft Ph. Eur. monograph on accelerator produced gallium-68 and found to comply with all requirements (Table 1). In all productions the radiochemical purity of the gallium- 68 chloride was above $99.9 \%$ and the radionuclidic purity (RNP) above $99.85 \%$ at EOP. That is, the combined content of coproduced gallium-66 and gallium-67 was in the range $0.029-0.15 \%$ of the total activity at EOP, i.e., much lower than the $2 \%$ limit given in the draft Ph. Eur. monograph. Based on RNP alone, this allows for a shelf-life (according to EU requirements) of up to $7 \mathrm{~h}$ of the purified $\left[{ }^{68} \mathrm{Ga}\right] \mathrm{GaCl}_{3}$ or of a gallium-68-labelled radiopharmaceutical prepared using the solution. Of particular importance is the low iron and zinc contents achieved in the purified $\left[{ }^{68} \mathrm{Ga}\right] \mathrm{GaCl}_{3}$ product (Table 1), being orders of magnitude lower than the limits given in the draft $\mathrm{Ph}$. Eur. monograph. That is, only $3.6 \mathrm{ng} / \mathrm{GBq}$ iron and $58 \mathrm{ng} / \mathrm{GBq}$ zinc were present in the $\left[{ }^{68} \mathrm{Ga}\right] \mathrm{GaCl}_{3}$ batch with the highest activity.

\section{Radiolabelling of DOTATATE}

To test the purity of the produced gallium-68 chloride, initial manual radiolabelling tests of DOTATATE were performed (Table 2). The $\left[{ }^{68} \mathrm{Ga}\right] \mathrm{Ga}$-DOTATATE was 
Table 1 Overview of selected $\left[{ }^{68} \mathrm{Ga}\right] \mathrm{GaCl}_{3}$ productions with associated quality control results analysed according to draft Ph. Eur. monograph on accelerator produced gallium-68. Limits given by the draft Ph. Eur. monograph are shown in parentheses. ND: Not determined. WP: White precipitate. EOP: End of purification

\begin{tabular}{|c|c|c|c|c|}
\hline Production run & 1 & 2 & 3 & 4 \\
\hline Zinc-68 mass & $315 \mathrm{mg}$ & $230 \mathrm{mg}$ & $240 \mathrm{mg}$ & $300 \mathrm{mg}$ \\
\hline Beam current \& time & $50 \mu \mathrm{A}, 30 \mathrm{~min}$ & $70 \mu \mathrm{A}, 30 \mathrm{~min}$ & $80 \mu \mathrm{A}, 2 \mathrm{~h}$ & $80 \mu \mathrm{A}, 2 \mathrm{~h}$ \\
\hline Charge ( $\mu \mathrm{Ah})$ & 25 & 36.2 & 163.4 & 164 \\
\hline GBq@EOP & 37 & 51 & 152 & 194 \\
\hline Appearance (Clear \& colorless) & $C \& C$ & $C \& C$ & $C \& C$ & $C \& C$ \\
\hline $\begin{array}{l}\text { Y-Spectrometry (Confirmed ID } \\
\text { by } 511 \& 1077 \mathrm{keV})\end{array}$ & Confirmed & Confirmed & ND & Confirmed \\
\hline $\mathrm{T} 1 / 2(62-74 \mathrm{~min})$. & 66.2 & 71.2 & 66.4 & 67.1 \\
\hline $\begin{array}{l}\text { Solid Phase Extraction (>90\% of } \\
\text { total radioactivity) }\end{array}$ & $91.3 \%$ & $95.0 \%$ & ND & $93.8 \%$ \\
\hline Precipitation with $\mathrm{AgNO}_{3}$ & WP & WP & WP & WP \\
\hline $\mathrm{pH}(<2)$ & $<2$ & $<2$ & $<2$ & $<2$ \\
\hline Contents of Fe $(<10 \mu \mathrm{g} / \mathrm{GBq})$ & $0.037 \mu \mathrm{g} / \mathrm{GBq}$ & $0.0077 \mu \mathrm{g} / \mathrm{GBq}$ & $0.0074 \mu \mathrm{g} / \mathrm{GBq}$ & $0.0036 \mu \mathrm{g} / \mathrm{GBq}$ \\
\hline Contents of $\mathrm{Zn}(<10 \mu \mathrm{g} / \mathrm{GBq})$ & $0.36 \mu \mathrm{g} / \mathrm{GBq}$ & $0.85 \mu \mathrm{g} / \mathrm{GBq}$ & $0.18 \mu \mathrm{g} / \mathrm{GBq}$ & $0.058 \mu \mathrm{g} / \mathrm{GBq}$ \\
\hline Bacterial endotoxins (< 175 IU/ V) & $<1.75 \mathrm{IU} / \mathrm{mL}$ & $<2 \mathrm{IU} / \mathrm{mL}$ & ND & $<1.85 \mathrm{IU} / \mathrm{mL}$ \\
\hline Y-Spectrometry (> 98\% Ga-68) & $99.95 \%$ & $99.89 \%$ & $99.85 \%$ & $99.97 \%$ \\
\hline Contents of Ga-66/67 (<2\%) & $0.047 \%$ & $0.11 \%$ & $0.15 \%$ & $0.029 \%$ \\
\hline Other radionuclidic impurities $(<0.1 \%)$ & Not detected & Not detected & Not detected & Not detected \\
\hline TLC $\left(>95 \% \mathrm{Ga}^{3+}\right)$ & $100 \%$ & $99.9 \%$ & 100\% (@+24 h) & $99.9 \%$ \\
\hline
\end{tabular}

Table 2 Produced activities at end of synthesis (EOS, not decay corrected) and associated AMA and purities for $\left[{ }^{68} \mathrm{Ga}\right] \mathrm{Ga}-P S M A-11$ and $\left[{ }^{68} \mathrm{Ga}\right] \mathrm{Ga}$-DOTATATE. n: Amount of peptide used for radiolabelling. TLC and TLC (colloid) denominates the RCP of $\left[{ }^{68} \mathrm{Ga}\right] \mathrm{Ga}-\mathrm{PSMA}-11$ from analysis for free and colloid gallium-68, respectively

\begin{tabular}{|c|c|c|c|c|c|}
\hline \multicolumn{6}{|c|}{$\left[{ }^{68} \mathrm{Ga}\right] \mathrm{Ga}-\mathrm{PSMA}-11$} \\
\hline Activity at EOS & $\mathrm{n}$ & AMA at EOS & RCP (HPLC) & TLC & TLC (colloid) \\
\hline GBq & $\mathrm{nmol}$ & $\mathrm{MBq} / \mathrm{nmol}$ & $\%$ & $\%$ & $\%$ \\
\hline 39.8 & 100 & 398 & 99.9 & 100 & 99.7 \\
\hline 42.9 & 100 & 429 & 99.8 & 100 & 99.9 \\
\hline \multirow[t]{3}{*}{72.2} & 100 & 722 & 98.2 & 100 & 99.8 \\
\hline & & Average: & 99.3 & 100 & 99.8 \\
\hline & & Std.dev.: & 1.0 & 0 & 0.1 \\
\hline \multicolumn{6}{|c|}{$\left[{ }^{68} \mathrm{Ga}\right] \mathrm{Ga}-\mathrm{DOTATATE}$} \\
\hline Activity at EOS & $\mathrm{n}$ & AMA at EOS & RCP (HPLC) & ITLC & \\
\hline GBq & nmol & $\mathrm{MBq} / \mathrm{nmol}$ & $\%$ & $\%$ & \\
\hline 0.87 & $34.8(50 \mu \mathrm{g})$ & 25 & 97.3 & 98.4 & \\
\hline 0.88 & $34.8(50 \mu \mathrm{g})$ & 25 & 98.2 & 98.4 & \\
\hline 0.75 & $34.8(50 \mu \mathrm{g})$ & 23 & 99.7 & 99.6 & \\
\hline \multirow[t]{3}{*}{3.22} & $348(500 \mu \mathrm{g})$ & 9.2 & 95.4 & 97.1 & \\
\hline & & Average: & 97.7 & 98.4 & \\
\hline & & Std.dev.: & 2.2 & 1.2 & \\
\hline
\end{tabular}


produced in high yields $(>95 \%)$ and in clinically acceptable apparent molar activities (AMA) of 9-25 MBq/nmol (non-optimized). Up to $3.2 \mathrm{GBq}$ of $\left[{ }^{68} \mathrm{Ga}\right] \mathrm{Ga}$-DOTATATE was produced. No attempts were made to increase the activity due to radiation protection issues of the manual method used.

\section{Radiolabelling of PSMA-11}

Radiolabelling of PSMA-11 was performed fully automated on a Modular-Lab PharmTracer module, hence much higher gallium- 68 activities could be used. The resulting $\left[{ }^{68} \mathrm{Ga}\right]$ Ga-PSMA-11 activities and corresponding RCP and AMA are summarized in Table 2. Up to $72.2 \mathrm{GBq}$ (approximately $2 \mathrm{Ci}$ ) of $\left[{ }^{68} \mathrm{Ga}\right] \mathrm{Ga}$-PSMA 11 was produced fulfilling key requirements in the draft Ph. Eur. monograph on $\left[{ }^{68} \mathrm{Ga}\right]$ Ga-PSMA-11 injection such as RCP, RNP and colloid formation as judged by radioHPLC, ITLC and gamma spectrometry (Gallium (68Ga) PSMA-11 Injection 2018). The amounts of unlabelled and colloid gallium- 68 were determined to $0 \%$ and $0.12-0.35 \%$, respectively. By HPLC, the RCPs were determined to be $99.3 \pm 1.0 \%$. The $\mathrm{pH}$ was measured to be between 7.0 and 7.6. The $\left[{ }^{68} \mathrm{Ga}\right] \mathrm{Ga}$-PSMA-11 was produced with an AMA of up to $722 \mathrm{MBq} / \mathrm{nmol}$ at EOS for the highest obtained activity of $72.2 \mathrm{GBq}$. The amount of unlabelled $\left[{ }^{68} \mathrm{Ga}\right] \mathrm{GaCl}_{3}$ separated by the SepPak C18 purification after the labelling step constituted only $2.3 \pm 0.2 \%$ of the total activity at EOS and was as such disregarded. Hence, the AMA of the $\left[{ }^{68} \mathrm{Ga}\right] \mathrm{GaCl}_{3}$ can be estimated to be approximately the same or higher than the AMA for the $\left[{ }^{68} \mathrm{Ga}\right]$ Ga-PSMA-11. The stability of the $\left[{ }^{68} \mathrm{Ga}\right]$ Ga-PSMA11 was evaluated over $2 \mathrm{~h}$ post EOS for this batch and no change was seen in RCP during this time $(98.2 \%$ at EOS, $98.6 \%$ at EOS $+2 \mathrm{~h}$ ) but a minor increase in colloid formation from $0.18 \%$ to $0.34 \%$ was observed. Hence, the $\left[{ }^{68} \mathrm{Ga}\right] \mathrm{Ga}-\mathrm{PSMA}-11$ was stable for at least $2 \mathrm{~h}$ despite the very high initial activity.

\section{Discussion}

At present, the supply of gallium-68 for medical imaging is primarily based on the $\left[{ }^{68} \mathrm{Ge}\right] \mathrm{Ge} /\left[{ }^{68} \mathrm{Ga}\right] \mathrm{Ga}$-generator. As these commercial generators can deliver only a limited amount of activity, and the demand for gallium-68 is increasing with the commercialization of kit-based radiopharmaceuticals, e.g. NETSPOT (DOTATATE), SomakitTOC (DOTATOC) and Illumet (PSMA-11), a future shortage of generators and gallium-68 may occur. Herein, we describe a high-yielding, automated production of this important isotope by irradiating solid targets of enriched ${ }^{68} \mathrm{Zn}$ metal on a biomedical cyclotron. This approach may serve as an important supplement to meet future demand.

By application of silver targets with enriched zinc-68 from ARTMS on the ARTMS QIS target system (Fig. 1), gallium-68 was produced by $13 \mathrm{MeV}$ proton irradiation at beam currents up to $80 \mu \mathrm{A}$. After irradiation, the solid target was pneumatically transferred from the cyclotron to a dissolution box in a hot cell (Fig. 2). The automated transfer comprises a very favourable and necessary feature as very high levels of radioactivity from estimated $>370 \mathrm{GBq}$ gallium-68 on the target were produced at EOB. Nelson et al. recently reported on a new method for cyclotron-based gallium-68 production by irradiation of zinc- 68 pellets with production yields up to $37.5 \pm 1.9 \mathrm{GBq}$ on target (non-purified) (Nelson et al. 2020). However, their method involves manual 
collection of the irradiated target and subsequent transport of the target to the hot cell in a lead shield by the operator. Such a method would lead to radiation protection issues if much higher radioactivities were routinely produced, as demonstrated in the current study. Here, automated target transfer and subsequent automatic separation and radiolabelling are mandatory to avoid excessive radiation exposure to the operator.

Samples of several productions were analysed according to the draft Ph. Eur. monograph on accelerator produced gallium-68 (Gallium (68Ga) Chloride (Accelerator-Produced) Solution for Radiolabelling 2017). The results of the tests are summarized in Table 1. Notably, the RCP and RNP were high and only minor amounts of gallium-66/ 67 were present, while no other radionuclidic impurities were detected by gamma spectrometry. Prolonged irradiation and higher beam currents expectedly improved the RNP and the AMA as judged by HPGe detection and ICP-OES, only $3.6 \mathrm{ng} / \mathrm{GBq}$ Fe and $58 \mathrm{ng} / \mathrm{GBq} \mathrm{Zn}$ were present in the $\left[{ }^{68} \mathrm{Ga}\right] \mathrm{GaCl}_{3}$ batch with the highest activity. This is more than 30 times lower than the iron contents of $0.13 \pm 0.07 \mu \mathrm{g} / \mathrm{GBq} \mathrm{Fe}$ found by Nelson et al. and $0.11 \pm 0.07 \mu \mathrm{g} / \mathrm{GBq}$ Fe found by Lin et al., which was the dominating metal impurity in these studies (Nelson et al. 2020; Lin et al. 2018). The improvement in the iron content in our method, which is highly important for obtaining a high AMA in subsequent labelling of radioconjugates, is due to the introduction of the second column containing LN resin in the separation, where Fe contaminants are bound. Importantly, the RNP was $\geq 99.89 \%$ and allowed for a shelf-life of the $\left[{ }^{68} \mathrm{Ga}\right] \mathrm{Ga}$ chloride of up to $7 \mathrm{~h}$ based on RNP alone.

To estimate the purity before ICP-OES results were obtained, the produced $\left[{ }^{68} \mathrm{Ga}\right] \mathrm{Ga}$ chloride was applied to radiolabel DOTATATE and PSMA-11. High labelling yield and AMA comparable to or higher than what is observed for the generator-produced isotope indicated a low amount of metallic impurities in the accelerator produced gallium-68. An Eckert-Ziegler synthesis module with a modified cassette and sequence directly connected to the separation module was applied to radiolabel PSMA-11 with very high levels of radioactivity $(>39.8 \mathrm{GBq})$. Several high activity productions with only $100 \mathrm{nmol}$ of PSMA-11 were performed yielding up to $72.2 \mathrm{GBq}\left[{ }^{68} \mathrm{Ga}\right] \mathrm{Ga}$-PSMA11 (uncorrected for decay; 23 min synthesis time), which was stabilized with $50 \mathrm{mg}$ sodium ascorbate and $1 \mathrm{~mL}$ ethanol in a $12 \mathrm{~mL}$ volume. The radioconjugate was tested for stability up to two hours after EOS (by HPLC, colour, TLCs for free and colloid gallium) and found stable in this formulation and very high AMA. RCP was higher than $98.5 \%$ after $2 \mathrm{~h}$.

In terms of patient doses, a batch of $70 \mathrm{GBq}\left[{ }^{68} \mathrm{Ga}\right] \mathrm{Ga}$-PSMA-11 would represent at least 10 doses for $50 \mathrm{~min} / \mathrm{scan}$ protocol for two simultaneously running PET-scanners. If PET scanner capacity is doubled to four scanners, the batch could deliver up to 2025 patient doses of $\left[{ }^{68} \mathrm{Ga}\right] \mathrm{Ga}-\mathrm{PSMA}-11$ from a single solid target based gallium-68 production.

Otherwise, a radioconjugate (or purified $\left[{ }^{68} \mathrm{Ga}\right] \mathrm{GaCl}_{3}$ ) of this stability and AMA could be transported to decentralized radiopharmacies possibly superseding the need for expensive generators on a continuous basis. Also, a generator carries the risk of germanium-68 breakthrough to the final product and eventually becomes long-lived radioactive waste (half-life of germanium-68: 271 days) after about 400 elutions, which needs to be disposed of. In comparison, no long-lived radioactive waste is produced by the cyclotron production route if the silver backing (containing some cadmium-109) is 
reused. Conversely, if only a limited amount of gallium-68 activity is needed (i.e. a few patient doses), a generator is much less technically demanding, very reliable and does not require trained personnel to perform separation and radiolabelling on synthesis modules or major capital investment in a cyclotron facility. Liquid cyclotron targets where acidic solutions containing zinc-68 salts are bombarded with protons, provide an alternative solution to get a small number of patient doses but the reported production yields of $<10 \mathrm{GBq}$ at $\mathrm{EOB}$ or approximately $5 \mathrm{GBq}$ at EOP are inferior to the solid target route (Pandey et al. 2019; Alves et al. 2018; Pedersen et al. 2019; do Carmo et al. 2020; Melissa et al. 2020). This method also carries the inherent risk of acids damaging targets and potentially cyclotron systems and require continuous target maintenance.

Other studies on solid target based $\left[{ }^{68} \mathrm{Ga}\right] \mathrm{GaCl}_{3}$ productions have been published recently (Schweinsberg et al. 2019). Alnahwi et al. reported on the production of $145 \mathrm{GBq}$ gallium-68, decay-corrected to $\mathrm{EOB}$, by proton irradiation of pressed zinc-68 targets with $35 \mu \mathrm{A}$ on target (Alnahwi et al. 2020). However, the use of targets made from pressed zinc powder with expectedly reduced heat transfer compared to solid zinc limits the maximum power density that can be absorbed in the target and thus, the maximum beam current. The resulting purified activity available at EOP for radiolabelling was not stated, although the authors reported an AMA of the produced $\left[{ }^{68} \mathrm{Ga}^{2} \mathrm{GaCl}_{3}\right.$ for a $20 \mathrm{~min}$ irradiation to be $28.3 \pm 6.8 \mathrm{GBq} / \mu \mathrm{mol}$. Radiolabelling of $21 \mathrm{nmol}$ DOTATATE with approximately $555 \mathrm{MBq}\left[{ }^{68} \mathrm{Ga}_{\mathrm{GaCl}}\right.$ at time of radiolabelling resulted in a labelling efficiency of $95 \pm 1.6 \%$, which is similar to the results obtained in the current study. However, the AMA of the $\left[{ }^{68} \mathrm{Ga}\right] \mathrm{Ga}$-DOTATATE is not reported by the authors but can be estimated to be approximately $26 \mathrm{MBq} / \mathrm{nmol}$ at time of labelling. This is in line with the AMA we observed for $\left[{ }^{68} \mathrm{Ga}\right] \mathrm{Ga}-D O T A T A T E$ using manual labelling procedures but inferior to the AMA of $\left[{ }^{68} \mathrm{Ga}\right] \mathrm{Ga}-\mathrm{PSMA}-11$ (and consequently the AMA of the $\left[{ }^{68} \mathrm{Ga}\right] \mathrm{GaCl}_{3}$ ) in our automated syntheses reaching as high as $722 \mathrm{MBq} / \mathrm{nmol}$ (range $398-722 \mathrm{MBq} / \mathrm{nmol}$ ). In comparison, the AMA obtained by Nelson et al. for $\left[{ }^{68} \mathrm{Ga}\right] \mathrm{Ga}$ chloride using DOTA-labelling was reported as $9.5 \pm$ $1.3 \mathrm{GBq} / \mu \mathrm{mol}$ (Nelson et al. 2020), and thus inferior to the AMA obtained in the present study.

In summary, the production method proposed here, to our knowledge, signifies a record high production of purified $\left[{ }^{68} \mathrm{Ga}\right] \mathrm{GaCl}_{3}$ and of $\left[{ }^{68} \mathrm{Ga}\right] \mathrm{Ga}$-PSMA-11 with high RNP, RCP and very high AMA. Furthermore, the highly automated method ensures a low radiation burden to the operator, despite the multi-Curie levels of radioactivity produced. As such, this production route features a favourable supplement to generator-produced gallium-68 capable of delivering tens of patient doses for gallium-68 tracers as demonstrated with record high quantities of $\left[{ }^{68} \mathrm{Ga}\right] \mathrm{Ga}-\mathrm{PSMA}-11$.

\section{Conclusion}

A high-yield method for direct cyclotron production of $\left[{ }^{68} \mathrm{Ga}\right] \mathrm{GaCl}_{3}$ has been demonstrated, leading to record high purified gallium-68 activities (194 GBq at EOP) and subsequent labelling of PSMA-11 (72.2 GBq) and DOTATATE. For production of $\left[{ }^{68} \mathrm{Ga}\right] \mathrm{Ga}$-PSMA-11 the entire process was highly automated from irradiation to formulation of the product and as such comprised a high level of radiation protection. The quality control results obtained for both $\left[{ }^{68} \mathrm{Ga}\right] \mathrm{GaCl}_{3}$ for radiolabelling and $\left[{ }^{68} \mathrm{Ga}\right] \mathrm{Ga}$ PSMA-11 and $\left[{ }^{68} \mathrm{Ga}\right] \mathrm{Ga}-\mathrm{DOTATATE}$ are promising for clinical use. 


\section{Abbreviations}

AMA: Apparent molar activities; DI: Deionized; EOB: End of bombardment; EOP: End of purification; EOS: End of synthesis; HPGe: High purity germanium detector; ICP-OES: Inductively coupled plasma optical emission spectrometry; ITLC: Instant thin layer chromatography; LN Resin: Di(2-ehtylhexyl)orthophosphoric acid-based resin; PSMA-11: PSMAHBED-CC; QIS: QUANTM Irradiation System ${ }^{\oplus}$; RadioHPLC: Radio High-performance liquid chromatography; RCP: Radiochemical purity; RNP: Radionuclidic purity; SPE: Solid phase extraction; TFA: Trifluoroacetic acid; TK200 Resin: Trioctylphosphine-based resin; ZR Resin: Hydroxamate-based resin

\section{Acknowledgements}

The authors would like to thank Triskem International for providing the resins.

\section{Authors' contributions}

$H T$, JK, JD, NL designed, performed, and analyzed experiments. MJ contributed with the ICP-OES analyses. JK, BH, SZ, AK, JC, $M C$, SB, PS contributed to the design and manufacture of the targets, fluid path or gallium-68 separation process development. HT, JD and JK wrote the manuscript. All authors contributed to, read and approved the final manuscript.

\section{Funding}

The research project was funded by the Department of Nuclear Medicine, Odense University Hospital, while ARTMS provided in-kind contributions to support this research.

\section{Availability of data and materials}

The datasets used and/or analyzed during the current study are available from the corresponding author on reasonable request.

\section{Ethics approval and consent to participate}

Not applicable.

\section{Consent for publication}

Not applicable.

\section{Competing interests}

The zinc-68 targets used within are Patent Pending.

The purification described within is Patent Pending.

OUH and DTU affiliated authors have no conflicts of interest to disclose.

\section{Author details}

${ }^{1}$ Department of Nuclear Medicine, Odense University Hospital, Kløvervænget 47, 5000 Odense, Denmark. ${ }^{2}$ Department of Clinical Research, University of Southern Denmark, Odense, Denmark. ${ }^{3}$ ARTMS, Vancouver, BC, Canada. ${ }^{4}$ The Hevesy Laboratory, Health Technology, Technical University of Denmark, Roskilde, Denmark. ${ }^{5}$ Life Sciences, TRIUMF, Vancouver, BC, Canada.

Received: 16 September 2020 Accepted: 23 November 2020

Published online: 07 January 2021

\section{References}

Alnahwi AH, Tremblay S, Ait-Mohand S, Beaudoin JF, Guerin B. Automated radiosynthesis of (68)Ga for large-scale routine production using (68)Zn pressed target. Appl Radiat Isot. 2020;156:109014.

Alves VH, Do Carmo SJC, Alves F, Abrunhosa AJ. Automated Purification of Radiometals Produced by Liquid Targets. Instruments. 2018:2(3):17.

do Carmo SJC, Scott PJH, Alves F. Production of radiometals in liquid targets. EJNMMI Radiopharmacy and Chemistry. 2020;5(1):2.

Gallium (68Ga) Chloride (Accelerator-Produced) Solution for Radiolabelling. Ph Eur. PAJPH/Exp. 14/T (18) 13 ANP(monograph 3109). 2017.

Gallium (68Ga) PSMA-11 Injection. Ph Eur. PA/PH/Exp. 14/T (16) 45 ANP R1(Monograph 3044). 2018.

Gleason Gl. A Positron Cow Appl Radiat Isot. 1960:8:90-4

Greene MW, Tucker WD. An Improved Gallium-68 Cow. Appl Radiat Isot. 1961;12(1-2):62-3.

Lin M, Waligorski GJ, Lepera CG. Production of curie quantities of (68)Ga with a medical cyclotron via the $(68) \mathrm{Zn}(\mathrm{p}, \mathrm{n})(68) \mathrm{Ga}$ reaction. Appl Radiat Isot. 2018;133:1-3.

Melissa ER, Carina S, Daniela S, Mara C, Andrew K, Brian GH, et al. EJNMMI Radiopharmacy and Chemistry. 2020. https://doi. org/10.21203/rs.3.rs-38981/v2.

Nelson BJB, Wilson J, Richter S, Duke MJM, Wuest M, Wuest F. Taking cyclotron (68)Ga production to the next level: Expeditious solid target production of (68)Ga for preparation of radiotracers. Nucl Med Biol. 2020;80-81:24-31.

Pandey MK, Byrne JF, Schlasner KN, Schmit NR, DeGrado TR. Cyclotron production of Ga-68 in a liquid target: Effects of solution composition and irradiation parameters. Nucl Med Biol. 2019;74-75:49-55.

Pedersen KS, Nielsen KM, Fonslet J, Jensen M, Zhuravlev F. Separation of Radiogallium from Zinc Using Membrane-Based Liquid-Liquid Extraction in Flow: Experimental and COSMO-RS Studies. Solvent Extr Ion Exch. 2019;37(5):376-91.

Schweinsberg C, Johayem A, Llamazares A, Gagnon K. The First Curie-Quantity Production of [68Ga]Ga-PSMA-HBED-CC. J Labelled Comp Radiopharm. 2019;62(S1):S276.

Yano Y, Anger HO. A Gallium-68 Positron Cow for Medical Use. J Nucl Med. 1964;5(6):485-7.

\section{Publisher's Note}

Springer Nature remains neutral with regard to jurisdictional claims in published maps and institutional affiliations. 